\title{
ASSESSMENT OF POSSIBLE ASSOCIATION BETWEEN ANTIOXIDANT LEVELS AND APOE GENE POLYMORPHISM IN DEMENTED SAUDI POPULATION
}

\author{
Ohoud A. Alomari ${ }^{1}$, Taha A.Kumosani ${ }^{1}$, Archana P. Iyer ${ }^{1}$, EtimadA. Huwait ${ }^{1}$, Mohammed S. \\ Bamaga $^{2}$, Naglaa M. Salim ${ }^{3}$, Charles G. Glabe ${ }^{4}$
}

\footnotetext{
${ }^{1}$ Biochemistry Department, Faculty of Science, King Abdulaziz University, Saudi Arabia.

${ }^{2}$ Laboratory Department, Alhada Armed Forces Hospital, Saudi Arabia.

${ }^{3}$ Geriatrics and Home Care Unit, Prince Mansour Armed Forces Hospital, Saudi Arabia.

${ }^{4}$ Molecular Biology and Biochemistry School of Biological Sciences University of California, Davis, USA.
}

Received - November 04, 2017; Revision - November 27, 2017; Accepted - January 13, 2018

Available Online - February 20, 2018

DOI: http://dx.doi.org/10.18006/2018.6(1).220.229

\author{
KEYWORDS \\ Dementia \\ Alzheimer's disease \\ APOE polymorphism \\ Antioxidant capacity \\ Lipid peroxidation
}

\begin{abstract}
To determine the possible associations between antioxidant serum markers and apolipoprotein $\mathrm{E}$ (APOE) genotypes in an elderly demented Saudi population. There were 80 subjects included in this study classified according to cognitive function as two groups control and demented patients. Antioxidant capacity and lipid peroxidation were measured using spectrophotometric analysis. APOE genotypes were determined using restriction enzyme analysis. Correlations of serum levels of antioxidant capacity and lipidperoxidation with APOE genotypes were assessed. Serum antioxidant capacity was significantly reduced in patients group in comparison to the control ( $\mathrm{p}$-value $=0.0125<0.05$ ). Also, lipid peroxidation level showed significantly higher concentration on patient compared to control group ( $\mathrm{p}$-value $=0.0167<0.05$ ). For APOE, three alleles (E2, E3 and E4) and four genotypes (E2/3, E3/3, E3/4 and E4/4) were identified in present study. There was a significant different between alleles and genotypes distribution in the study groups as the frequency of E4 was higher in the subjects with dementia compare toin control ( $\mathrm{p}$-value $=0.0168<0.05$ ) and $(\mathrm{p}$-value $=0.0447<0.05$ ), respectively. However, no association was found between APOE status and serum levels of antioxidant capacity and lipid peroxidation. In conclusion, no correlation between antioxidant capacity or lipid peroxidation levels and APOE genotypes. They are independent risk factors for dementia in the Saudi population.
\end{abstract}

* Corresponding author

E-mail: arch729@gmail.com (Archana P. Iyer)

Peer review under responsibility of Journal of Experimental Biology and Agricultural Sciences.

Production and Hosting by Horizon Publisher India [HPI] (http://www.horizonpublisherindia.in/).

All rights reserved.
All the article published by Journal of Experimental Biology and Agricultural Sciences is licensed under a Creative Commons Attribution-NonCommercial 4.0 International License Based on a work at www.jebas.org.

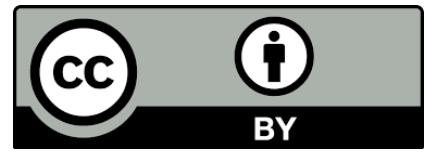




\section{Introduction}

Inrecent years, healthcare services are improved that lead to increase in longevity and life expectancy. Dementia is not considered as a normal part of aging, but its prevalence become more common among an elderly population (Prince et al., 2013; Castro-Chavira et al., 2015). Dementia is an acquired cognitive impairment syndrome with slow progression that can be caused by a range of diseases and injuries to the brain as neurocognitive disorder (American Psychiatric Association, 2013; Thakur, 2015; Chen et al., 2016). It is characterized by progressive loss of cognitive and intellectual functions, especially memory and behavioral disabilities that interferes with a person's daily life (World Health Organization, 2012; Alzheimer's Association, 2017). Causes of dementia can vary, depending on the types of brain changes that may be taking place and there are manygenetic, lifestyle, vascular risk factors including in its pathogenesis. The most common subtype of dementia is Alzheimer's disease and other types include Vascular dementia, Lewy body dementia and Frontotemporal dementia (World Health Organization, 2012; Alzheimer's Association, 2017). However, it is common for people to have these pathologies together as mixed dementia (Jellinger, 2007; Lee, 2011; Castro-Chavira et al., 2015).

In the case of most progressive dementia there is no known cures available (Williams et al., 2010; Lundkvist et al., 2014; Alzheimer's Association, 2017).Though, there are multiple pharmacological and non-pharmacological treatments that have been proven to slow disease progression and treat symptoms (Rosini et al., 2014; Jedenius et al., 2015; D’Onofrio et al., 2016; Alzheimer's Association, 2017).

The genetic aspects have been indicated to play an important role in the dementia development. The different subtypes of dementia have different structural genomics (Ferencz \& Gerritsen, 2015). For example, Alzheimer's disease has more than 200 genes that might be involved in its pathogenesis (Cacabelos, 2008). In general, only apolipoprotein E4 gene is consistent between studies as the strongest genetic risk factor linked tomost common dementia subtype in various populations (Harold et al., 2009; Percy et al., 2014; Alzheimer's Association, 2017).

The human apolipoprotein E (APOE) is a 299 amino acid glycoprotein that plays a key role in lipid transport and lipoprotein metabolism through both the vascular and nervous systems by binding to members of the low-density lipoprotein receptor family (Bu, 2009). The APOE gene is mapped to chromosome 19 which consists of four exons and three introns. The structural gene locus for APOE is polymorphic having three common different alleles APOE2 (cys112, cys158), APOE3 (cys112, arg158) and APOE4 ( $\arg 112, \arg 158)$. This amino substitution results in not only structural differences, but also physiologic differences such as their binding affinity for specific lipoprotein receptors, antioxidant properties, inflammatory responses and neuronal processes such as development and plasticity. Additionally, each of the APOE alleles is associated with differing risks of specific diseases (Mahley et al., 2006; Frieden \& Garai, 2012; Liu et al., 2013).

The E2, E3 and E4 alleles have a world-wide frequency of 8.4\%, $77.9 \%$ and $13.7 \%$, respectively (Riddell et al., 2008; Holtzman et al., 2012; Kang et al., 2016). There are three homozygous (E4/4, $\mathrm{E} 3 / 3$ and E2/2) and three heterozygous (E2/4, E3/4 and E2/3) genotype.

The prevalence of APOE alleles and genotypes in Saudi population was closed to other population. A study on healthy unrelated Saudi subjects observed that the allelic frequencies of APOE were $79 \%$ for $\mathrm{E} 3,15 \%$ for $\mathrm{E} 4$ and $6 \%$ for $\mathrm{E} 2$ and five genotypes were detected (E3/E3, E4/E4, E2/E3, E2/E4 and E3/E4) with prevalence as percentage $63,2.5,8.5,1$ and 25, respectively (Awad \& El-Tarras, 2011)

The APOE3 is most common and considered with normal lipid metabolism. However, APOE2 and APOE4 isoforms are related to abnormal lipid metabolism and associated with risk of many diseases.

The APOE4 has been presented more harmful effects in the brain as it associated with neuronal mitochondrial dysfunction, decrease GABAergic interneuron selectivity, greater neuronal inflammation, less efficient neuronal repair, blood brain barrier (BBB) dysfunction, $\mathrm{A} \beta$ accumulation, reduction in cerebral blood flow and hypoxia (Zlokovic, 2011; Leduc et al., 2011; Ringman et al., 2012; Villeneuve et al., 2014).

The frequency of the E4 allele is dramatically increased risk factor of most common form of dementia while the E2 allele being protective relative to the prevalent E3 allele (Corder et al., 1993; Dewji \& Singer, 1996; Huang, 2010; Liu et al., 2013; Vos et al., 2013). Also, APOE4 carriers develop dementia 8-20 years earlier than non-carriers (Bertram \& Tanzi, 2008; Verghese et al., 2011; Mahley \& Huang, 2012; Panza et al., 2012).

The APOE4 has been extensively studied in major subtypes of dementia including Alzheimer's disease, mild cognitive impairment, vascular dementia diseases, Lewy body disease and frontotemporal dementia, however most studies have failed to report associations between APOE4 and susceptibility to Parkinson's disease and PD-associated dementia (Rubino et al., 2013; Zhou et al., 2014; Wang et al., 2014; Rohn, 2014; Bras et al., 2014; Walker et al., 2015; Yan et al., 2016; Chen et al., 2016).

On the other hand, increasing evidence demonstrates that oxidative stress causes damage to cell function with aging and it is also involved in a number of age-related neurodegenerative 
disorders such as dementia (Niedzielska et al., 2016). In some circumstances the production of reactive oxygen species and reactive nitrogen species can exceed the endogenous antioxidant ability to destroy them and an oxidative imbalance occurs (PhamHuy et al., 2008; Halliwell \& Gutteridge, 2015). This event results in cellular oxidative stress and subsequent molecular oxidative damage, which can translate into altered cellular functions and as final result, cell death (Halliwell \& Gutteridge, 2015). The cerebral tissue is very prone to oxidative imbalance because it is very rich in polyunsaturated fatty acids (PUFAs), has a high metabolic oxidative rate and content of transition metals which together act as potent prooxidants. In addition to brain insufficient antioxidant defines. Depending on the substrate attacked by the free radicals, oxidative stress will manifest as protein, DNA and RNA oxidation or lipid peroxidation (Friedman, 2011).

Increase in oxidation markers and decrease in antioxidant markers in blood, cerebrospinal fluid and in postmortem brain samples of patients with dementia are reported in many studies (Cristalli et al., 2012; Popa-Wagner et al., 2013; Schrag et al., 2013; Chang et al., 2014; Niedzielska et al., 2016).

The association between APOE genotype and the cellular stress response in dementia patients yielded inconsistent results. While some studies have shown that APOE4 is positively associated with markers of oxidative stress and negatively associated with antioxidant defense markers compared to APOE3 and APOE2 (Chico et al., 2013; Dose et al., 2016). Non significant differences was reported between the APOE isoforms and specific antioxidative properties by Zito et al. (2013) and López-Riquelme et al. (2016). The overall purpose of this research is to evaluate the possible relationship between APOE genotype and serum level of antioxidant in Saudi patients with dementia of different types.

\section{Methods and materials}

\subsection{Subjects}

Eighty elderly Saudi subjects included in this research. They were classified into two groups viz., (i) Control group was recruited from out-patient sections of the Department of Laboratory, Alhada Armed Force Hospital in Taif region (ii) another group was patients with dementia were recruited from theHome Visit Unit, Prince Mansour Military Hospital in Taif region, Saudi Arabia from January to May 2017. The diagnosis of mild, moderate or severe dementia accomplished by a geriatric consultant based on physical examination and neurological tests. Each group has (20 Females, 20 Males) totally 40 subjects with onset age of 65 years or older.

Written consents were obtained from subjects or their caregivers. Unit of Medical Research Committee in Armed Forces Hospitals approved this study. The experimental work of this study was conducted at the Experimental Biochemistry Unit and Central Labs, King Fahd Medical Research Centre (KFMRC), Jeddah, Saudi Arabia.

\subsection{Blood Collections}

Blood collections were performed according to the standard process. Whole blood samples were drawn from the antecubital vein of patients with dementia and age-matched control. Blood sample were collected in gel serum separation tubes (SST) for antioxidant capacity and lipid peroxidation tests and into (K2EDTA) anticoagulated tubes for DNA extraction.Collected blood samples were kept in a thermal insulated box along with packs of ice through transport. The yellow gel tubes were allowed to clot at room temperature for 30 minutes and centrifuged at $2500 \mathrm{xg}$ for $10 \mathrm{~min}$ at $4^{\circ} \mathrm{C}$. Then, serum supernatant was removed and divided into $0.5 \mathrm{ml}$ aliquots and stored at around $-80^{\circ} \mathrm{C}$ until analysis. The Lavender tubes were used for DNA extraction stored in refrigerator at $4^{\circ} \mathrm{C}$.

\subsection{Antioxidant Capacity and Lipid peroxidation Assessment}

Ferric Reducing Antioxidant Power (FRAP) as antioxidant capacity indicator and Thiobarbituric Acid Reactive Substances (TBARS) concentrations as one of final product of lipid peroxiation were measured according to kitmanufacturer protocols. FRAP Aassy Kit (Cellbiolab,USA, Cat. no. STA-859) and TBARS Assay Kit (Caymanchem USA, Cat. no. 10009055).

\subsection{Measurement of Antioxidant capacity}

Ferric Reducing Antioxidant Power (FRAP) assay is redoxdependent colorimetric assay. The principle based on the highlycited work of Benzie \& Strain(1996) which antioxidants present within the sample donated electrons to Ferric iron $\left(\mathrm{Fe}^{+}{ }^{+}\right)$which lead to reduced them to the ferrous form $\left(\mathrm{Fe}^{+}\right)$. The iron colorimetric probe complex developed a dark blue color produced upon reduction, which can be measured at 540-600 nm (Benzie \& Strain, 1996).

\subsection{Measurement of Lipid Peroxiation}

A well-established method for screening and monitoring lipid peroxidation is the measurement of Thiobarbituric Acid Reactive Substances (TBARS) which are naturally present in biological samplesand itsreported in malonaldehyde (MDA) equivalents, a compound that results from the decomposition of polyunsaturated fatty acid lipid peroxides.In the presence of heat and acid, MDA in the samples was reacted with TBA to produce a colored end product which can be measured calorimetrically at wavelength $530-540 \mathrm{~nm}$. 


\subsection{DNA Extraction}

Genomic DNA was extracted from whole blood samplesusing Gene JET Whole Blood Genomic DNA Purification Mini Kit (Thermo Scientific, USA, Cat. no. K0782). The extracted DNA was stored at $-20^{\circ} \mathrm{C}$ for PCR amplification. Concentration and purity of the extracted DNA was calculated automatically by Nanodrop2000c instrument from Thermo Scientific (USA).

\subsection{Polymerase chain reaction}

For Polymerase Chain Reaction (PCR), the reactions were prepared using GoTaq ${ }^{(\mathrm{R})}$ Green PCR Master Mix (Promega, USA, Cat. no. M7122). The primers were developed from Macrogen. The forward primer was (5'-ACA GAA TTC GCC CCG GCC TGG TAC AC-3') and the reverse one was (5'-TAA GCT TGG CAC GGC TGT CCA AGG A-3')as described by Emi et al.(1988). The reaction mix $(50 \mu \mathrm{l})$ contained $2 \mathrm{X}$ reaction buffer, $4 \mu \mathrm{M} \mathrm{MgCl} 2,4 \mu \mathrm{M}$ deoxyribonucleoside triphosphates, $0.2 \mu \mathrm{M}$ of each primer, $0.45 \mathrm{U}$ Taq DNA polymerase, $0.1 \mu \mathrm{M}$ of Dimethyl Sulfoxide (DMSO) and 10-30 ng of DNA template. The total reaction volume was made up to $50 \mu 1$ with nuclease free water. The amplification conditions consisted of an initial denaturation at $95^{\circ} \mathrm{C}$ for $1 \mathrm{~min}, 35$ cycles of denaturation at $95^{\circ} \mathrm{C}$ for $1 \mathrm{~min}$, an annealing at $65{ }^{\circ} \mathrm{C}$ for $1 \mathrm{~min}$ and an extension at $72{ }^{\circ} \mathrm{C}$ for $1 \mathrm{~min}$, followed by a final extension at $72^{\circ} \mathrm{C}$ for $5 \mathrm{~min}$ and ended at hold at $4{ }^{\circ} \mathrm{C}$. To verify PCR product, $2 \%$ agarose ethidium bromide stained gel was used.

\subsection{Genotyping of Apolipoprotein E}

Amplified PCR products were digested with HhaI restriction enzyme which was collected from Thermo Scientific (Cat. No. ER1851). This enzyme was used according to the supplier recommended protocols (Thermo Scientific, USA).By using the thermal cycler, the reaction was incubated in $37^{\circ} \mathrm{C}$ for 16 hour which is the activation temperature, then the enzyme was inactivated by adding $0.5 \mathrm{M}$ EDTA, $\mathrm{pH}$ 8.0. The restriction enzyme results were determined in $8 \%$ non-denaturing polyacrylamide ethidium bromide stained gels.

\subsection{Statistical analysis}

All statistical analyses were performed using computer program package (SPSS, 16.0.). Descriptive data were given as mean \pm standard deviation (SD). Differences among groups were tested using the t-test. Differences in the distribution of the alleles and genotypes between the females and males in each groups were examined with the chi-square analysis. Rare genotypes ( $n=0$ in any group) were excluded from the analysis. Mean of data was compared for different genotypes by analysis of variance (ANOVA). The differences in genotype frequencies were considered statistically significant for $\mathrm{p}$ value $<0.05$.

\section{Results}

\subsection{The Main Characteristics of the Study Group}

The subjects in this study were classified according to cognitive function as two groups control (20 Females, 20 Males) and demented patients (20 Females, 20 Males) totally 40 subjects in each group. The biochemical parameters of the two groups are shown in (Table 1). The age between demented patients and control was exhibited a non-significant differences $\mathrm{p}$ value $=$ $0.0683>0.05$. The antioxidant capacity (FRAP) values between demented patients and control showed a significant difference $\mathrm{p}$ value $=0.0125<0.05$, but non-significant between females and males in each group. The lipid peroxidation (MDA) values are

Table1 Biochemical Characteristics of Control and Dementia

\begin{tabular}{|c|c|c|c|c|c|c|c|}
\hline \multirow[t]{2}{*}{ Parameters } & \multicolumn{2}{|c|}{$\begin{array}{l}\text { Non-Demented } \\
\text { Mean } \pm \text { SD }\end{array}$} & \multicolumn{2}{|c|}{$\begin{array}{l}\text { Demented } \\
\text { Mean } \pm \text { SD }\end{array}$} & \multirow[t]{2}{*}{$P 1$} & \multirow[t]{2}{*}{$P 2$} & \multirow[t]{2}{*}{$P 3$} \\
\hline & Female $n=(20)$ & Malen $=(20)$ & Female $\mathrm{n}=(20)$ & Male $n=(20)$ & & & \\
\hline Age (years) & $76.67 \pm 2.64$ & $78.46 \pm 5.68$ & $78.61 \pm 5.23$ & $81.35 \pm 6.93$ & 0.2826 & 0.1813 & 0.0683 \\
\hline $\begin{array}{l}\text { (FRAP) Assay } \\
\text { Iron (II) Concentration }(\mu \mathrm{M})\end{array}$ & $199.79 \pm 58.74$ & $189.57 \pm 84.75$ & $164.81 \pm 55.12$ & $155.01 \pm 35.81$ & 0.6601 & 0.5087 & $0.0125 *$ \\
\hline SUM & \multicolumn{2}{|c|}{$194.68 \pm 72.16$} & \multicolumn{2}{|c|}{$159.91 \pm 46.15$} & & & \\
\hline $\begin{array}{l}\text { (TBARS) Assay } \\
\text { MDA Concentration }(\mu \mathrm{M})\end{array}$ & $7.97 \pm 3.80$ & $9.02 \pm 3.21$ & $13.10 \pm 6.43$ & $9.26 \pm 4.95$ & 0.3516 & $0.0413 *$ & $0.0167 *$ \\
\hline SUM & \multicolumn{2}{|c|}{$8.49 \pm 3.51$} & \multicolumn{2}{|c|}{$11.18 \pm 5.99$} & & & \\
\hline
\end{tabular}
and Demented; The values represented as the mean \pm standard deviation (SD) 
significantly different $\mathrm{p}$-value $=0.0167<0.05$ between demented patients and control, also between females and males in demented group p-value $=0.0413<0.05$

\subsection{Analysis of the HhaI Polymorphisms in the APOE Gene}

The PCR product in samples collected from Saudi subjects, 244-bp has been shown in figure 1 . The samples were digested with the Hhal restriction enzyme. The main fragment lengths of digested products for E2 were 91 and $83 \mathrm{bp}, \mathrm{E} 3$ were 91, 48 and $35 \mathrm{bp}$, and for E4 were 72, 48 and $35 \mathrm{bp}$ (Figure 2). For APOE, three alleles and four genotypes (E2/3, $\mathrm{E} 3 / 3, \mathrm{E} 3 / 4$ and E4/4) were identified. The allele frequencies were $87.5 \%$ for $\mathrm{E} 3,10.6 \%$ for $\mathrm{E} 4$ and $1.9 \%$ for E2. The most frequent genotype was the E3/3 with76.2\% allele frequency. On the other hand, none of the studied subjects had E2/4 or E2/2 genotype. The distribution of the allele and genotypes of ApoEhas been shown in table 2.

3.3 Statistical Analysis of the APOE Alleles and Genotypes Frequencies in Saudi Subject with and without Dementia

Frequencies of APOE alleles and genotypes in the two studied groups with respective to gender were shown in Table 3. The distribution of alleles frequency of E3, E4 and E2 differ significantly between demented and control groups $(p=0.0168<0.05$ ). E3 allele was more frequent in both control and patient groups. The frequency of E2 allele was more frequent in control group compared with demented patients. In contrast, the frequency of E4 allele was more frequent in demented patients compared with control group. Also, it was highly significant between females and males ofdemented group ( $\mathrm{p}$ value $=0.0423<0.05)$. The distribution of APOE genotype was significantly different between controls and patients (p-value $=0.0447<0.05)$. Further, E3/E3 genotype occurred more frequently in both controls and patients. On the other hand, the frequency of E3/E4 and $\mathrm{E} 4 / \mathrm{E} 4$ were more frequent in demented group compared with controls.

\subsection{Characteristics of Subjects According to their APOEGenotype}

The study of sample characteristics with respect to APOEgenotypes are shown in table 4. In all polymorphisms, therewere no significant differences

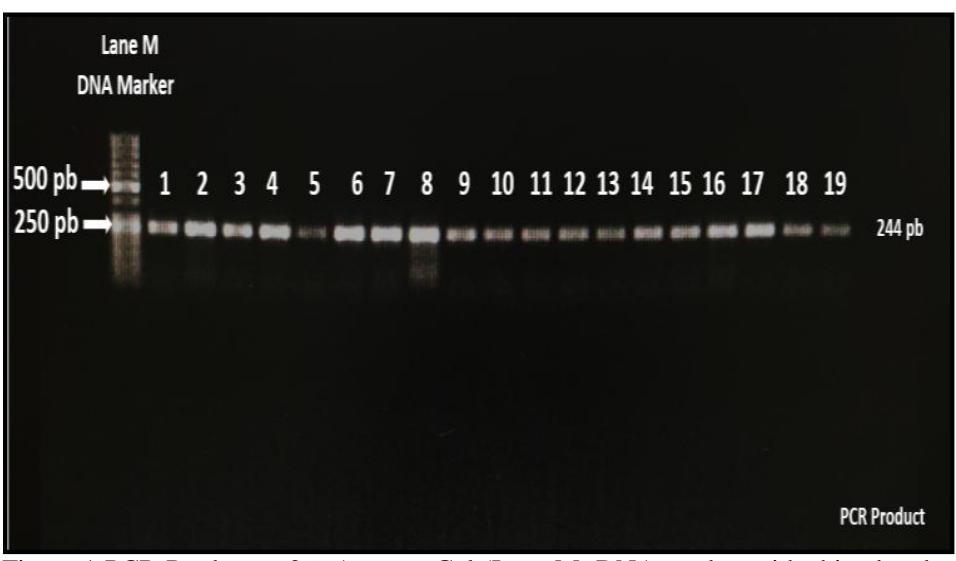

Figure 1 PCR Producton 2\% Agarose Gel (Lane M: DNA marker with shine band at 500pb and $250 \mathrm{pb}$; Lanes 1-19: 244 bp represent amplified APOE gene from samples)

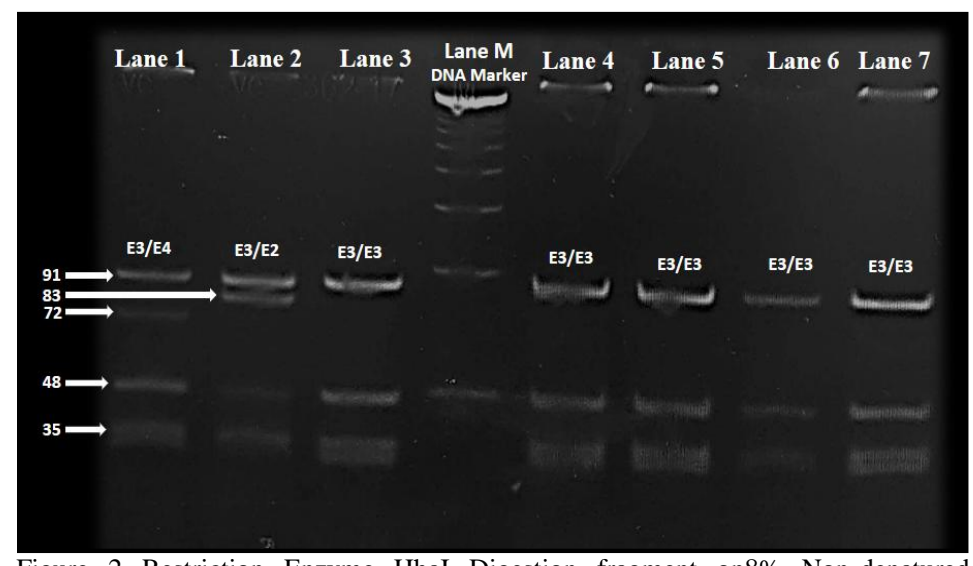

Figure 2 Restriction Enzyme HhaI Digestion fragment on8\% Non-denatured Polyacrylamide Gel Showing (Lane M: DNA marker, Lanes 1: E3/E4 - 91 bp, 72 bp, $48 \mathrm{bp}$ and 35 bp; Lane 2: E3/E2 - 91 bp, 83 bp, 48 bp and 35 bp; Lane 3, 4, 5, 6, 7: E3/E3 - 91 bp, 48 bp and 35 bp)

Table 2 Frequency and Percentage of the Entire Alleles and the Genotypes of APOE Gene in Elderly Saudi Subject with and without Dementia

\begin{tabular}{|c|c|c|c|c|c|c|}
\hline $\begin{array}{c}\text { APOE gene } \\
\text { Polymorphism }\end{array}$ & $\begin{array}{c}\text { Non- } \\
\text { Demented } \\
\mathrm{n}=40\end{array}$ & $(100 \%)$ & $\begin{array}{c}\text { Demented } \\
\mathrm{n}=40\end{array}$ & $(100 \%)$ & $\begin{array}{l}\text { Total } \\
\mathrm{n}=80\end{array}$ & $(100 \%)$ \\
\hline \multicolumn{7}{|c|}{ Allele } \\
\hline E3 & 75 & 93.7 & 65 & 81.2 & 140 & 87.5 \\
\hline E4 & 3 & 3.8 & 14 & 17.6 & 17 & 10.6 \\
\hline E2 & 2 & 2.5 & 1 & 1.2 & 3 & 1.9 \\
\hline Total & 80 & 100 & 80 & 100 & 160 & 100 \\
\hline \multicolumn{7}{|c|}{ Genotype } \\
\hline E3/E3 & 35 & 87.5 & 26 & 65 & 61 & 76.2 \\
\hline E3/E4 & 3 & 7.5 & 12 & 30 & 15 & 18.8 \\
\hline E4/E4 & 0 & 0 & 1 & 2.5 & 1 & 1.2 \\
\hline E3/E2 & 2 & 5 & 1 & 2.5 & 3 & 3.8 \\
\hline Total & 40 & 100 & 40 & 100 & 80 & 100 \\
\hline
\end{tabular}


Table 4 Characteristics of Subjects with and without Dementia According to their APOEGenotype

\begin{tabular}{|ccccc|}
\hline Variables & $\begin{array}{c}\mathrm{E} 3 / \mathrm{E} 3 \\
\mathrm{n}=(61)\end{array}$ & $\begin{array}{c}\text { E3/E4,E4/E4 } \\
\mathrm{n}=(16)\end{array}$ & $\begin{array}{c}\mathrm{E} 3 / \mathrm{E} 2 \\
\mathrm{n}=(3)\end{array}$ & $\begin{array}{c}\text { P-value } \\
\text { ANOVA }\end{array}$ \\
\hline Age (years) & $77.2 \pm 6.38$ & $78.0 \pm 5.34$ & $82.0 \pm 17.58$ & 0.4708 \\
\hline $\begin{array}{c}\mathbf{F e}^{2+} \text { Concentration } \\
(\boldsymbol{\mu M})\end{array}$ & $178.62 \pm 66.38$ & $164.16 \pm 46.48$ & $220.51 \pm 50.24$ & 0.3447 \\
\hline $\begin{array}{c}\text { MDA } \\
\text { Concentration } \\
(\boldsymbol{\mu M})\end{array}$ & $9.60 \pm 4.98$ & $11.58 \pm 5.27$ & $5.42 \pm 1.71$ & 0.1156 \\
\hline
\end{tabular}

Values are mean \pm SD FRAP value $=$ Antioxidant Activity

MDA value $=$ Lipid Peroxidation

(p-value > 0.05) in age, antioxidant capacity and lipid peroxidation level between different genotype groups.

\section{Disucssion}

Studies on the influence of the APOE genotype on antioxidant activities in dementia patients yielded conflicting results. Apolipoprotein $\mathrm{E}$ has been investigated in several experimental settings regarding its role in cellular oxidative stress generation and antioxidant responses in isoform dependent manner. In relation to that, it has been reportedthat patients carrying E4 allele are more susceptible to lipid peroxidation. On the other hand, the E2 and E3 isoforms possess greater antioxidant activity (Pulido et al., 2005; Baldeiras et al., 2008; Chico et al., 2013; Dose et al., 2016). Other studies showed that APOE genotype and oxidative stress or antioxidant activities are independent risk factors for dementia (Ihara et al., 2000; Zito et al., 2013; López-Riquelme et al., 2016).

Findings of present study suggested the involvement of oxidative stress in dementia pathogenesis. The mean value of serum antioxidant capacity was significantly reduced in dementia patients group ascompared to the control $(p$-value $=0.0125<0.05)$ but there was no significant difference between females and males in each group.Similar results are reported by various researchers (Guidi et al., 2006; Negahdar et al., 2015; Moslemnezhad et al., 2016). In addition, MDA levels as lipid peroxidation indicator showed a significantly higher concentration on patient compared to control group ( $\mathrm{p}$-value $=0.0167<0.05$ ). Also, MDA levels were significantly higher in females comparing to male in dementia group ( $\mathrm{p}$-value $=0.0413<0.05$ ). While in case of control group, non-significant difference was reported between females and males group. This observation was similar from previous publications that reported significant differences not only in MDA levels but also in various oxidative stress biomarkers like protein oxidation and DNA oxidation (Schrag et al., 2013; Chang et al., 2014; Iova et al., 2014; López-Riquelme et al., 2016). Demented females had higher levels of malondialdehyde than males that might be due to their higher prevalence of vascular diseases and lipid disorder.

In general, results of present study consist with the hypothesis that suggest the role of oxidative stress in the physiopathology of dementia as it is involved in the crucial events leading to the neural death (Cervellati et al., 2014; Luca et al., 2015). However, other studies have shown no clear association between oxidative stress and dementia (Pulido et al., 2005; Zafrilla et al., 2006; Sekler et al., 2008; Chang et al., 2014). On the other hand, demented patients were slightly older than control groups that could also responsible for increased oxidative stress and decrease antioxidant markers (Cervellati et al., 2014).

Apolipoprotein E is fundamentally involved in the lipid homeostasis in an isoform-dependent manner. The APOE3 is often associated with normal cholesterol levels. On the other hand, APOE2 and APOE4 isoforms are related to lipid abnormalities and risks of specific diseases (Huang \&Mahley, 2014).

The APOE4 was shown to be associated with age-related diseases, including Alzheimer's disease, therefore an increase in mortality risk with advanced age (Dose et al., 2016). The APOE4 is also associated with an increased risk of mild cognitive impairment, vascular dementia diseases, Lewy body disease and frontotemporal dementia. However, most studies have failed to report associations between APOE4 and susceptibility to Parkinson's disease and PD-associated dementia (Rubino et al., 2013; Zhou et al., 2014; Wang et al., 2014; Rohn, 2014; Walker et al., 2015; Yan et al., 2016; Chen et al., 2016).

The frequency of the APOE alleles showed that the most common isoform was APOE3 in demented patients and control as $81.2 \%$ and $93.7 \%$, respectively. Moreover, the frequency of allele E4 was higher in subjects with dementia as $17.6 \%$ compared to $3.8 \%$ in control, respectively. Also, it was more frequent in females compared to males in demented group (value of $\mathrm{p}=0.0423$ ). Finally, the frequency of allele E2 was less common as $2.5 \%$ and $1.2 \%$, respectively in control and demented group. Concluded that there was a significant difference between alleles distribution in study groups (value of $\mathrm{p}=0.0168$ ).

In the same manner, the genotype frequency has significantly different between demented patients and control group (value of $\mathrm{p}=0.0447)$. Four genotypes were detected (E3/E3, E3/E4, E4/E4, and E3/E2) with prevalence percentage of $(65,30,2.5$ and 2.5 , respectively) in demented patients and (87.5, 7.5, 0 and 5, respectively) in control group. These indicate that APOE4 is associated with dementia and cognitive decline, while APOE2 has protective effects. Our results were similar to those reported in many previous investigations (Farrer et al., 1997; 
Borenstein et al., 2010; Chen et al., 2016). In contrast to Saudi study that concluded that APOE4 allele was equally frequent in patients with or without dementia. The differences in the prevalence of E3/E3 and E3/E4 in persons with and without dementia were nonsignificant $(\mathrm{p}=0.2015)$. Other genotypes with an E2 allele were absent in the tested population (Al-Khedhairy, 2004).

In our research, subjects were classified by their ApoE genotype into three groups: sixty-one subjects ( 26 dementia patients and 35 controls) were included in the ApoE $3 / 3$ group, sixteen subjects in the APOE $3 / 4$ or $4 / 4$ group (13 dementia patients and 3 controls) and three subjects in the APOE $3 / 2$ group ( 1 dementia patient and 2 controls). Then, we examined the association of antioxidant capacity and lipid peroxidation levels with different APOE genotypes.

Then, we examined the association of antioxidant capacity and lipid peroxidation levels with different APOE genotypes. Data analysis showed that there is no significant difference was found between the antioxidant level and lipid peroxidation results according to the differences in ApoE genotypes ( $\mathrm{p}=0.3447$ and $0.1156>0.05$ ), respectively. These findings support the hypothesis that demonstrate the presence of $\mathrm{E} 4$ allele and decline antioxidant level with elevated lipid peroxidation are independent risk factors for dementia. and they are contribute to the pathogenic cascade in dementia by different pathways (Ihara et al., 2000; Zito et al., 2013; López-Riquelme et al., 2016). In conclusion, our study indicated that the APOE4 allele and oxidative stress are separated risk factor in the pathogenesis of dementia in the Saudi population.

Results of this studyrecommend that using the same methodology with larger sample size in the same population to determine whether APOE gene and oxidative stress are work together in the pathogenesis of dementia or separately. Moreover, supplementary Antioxidants are recommended to patients with dementia.

\section{Acknowledgment}

I would like to thank king Abdul Aziz City for Science and Technology for its financial support to the project research number (P-S- 38-1994) that enabled me in the provision of requirements and necessary chemical substances for the research. Also this project was funded by the Deanship of Scientific Research (DSR) at King Abdulaziz University, Jeddah, under grant no. 3-141-36 HiCi. The authors, therefore, acknowledge with thanks DSR for technical and financial support.

\section{Conflict of Interest}

The author(s) declared no potential conflicts of interest with respectto the research or publication of this article.

\section{References}

Al-Khedhairy AAA (2004) Apolipoprotein E polymorphism as a predictor for cognitive decline and dementia in the Saudi general population over 65 years. Genetics and Molecular Biology 27: 331-334.

American Psychatric Association (2013) Diagnostic and statistical manual of mental disorders (DSM-5®)Arlington: American Psychiatric Publishing.

Alzheimer's Association (2017) 2017 Alzheimer's disease facts and figures. Alzheimer's \& Dementia 13: 325-373.

Awad N, El-Tarras A (2011) Analysis of the APO B R3500Q mutation and APOE polymorphism in Taif Saudi population using polymerase chain reaction-reveres hybridization technique. Journal of Molecular Biomarkers \& Diagnosis 2: 109. doi:10.4172/2155-9929.1000109.

Baldeiras I, Santana I, Proença MT, Garrucho MH, Pascoal R, Rodrigues A, Duro D, Oliveira CR (2008) Peripheral oxidative damage in mild cognitive impairment and mild Alzheimer's disease. Journal of Alzheimer's Disease 15: 117-128.

Benzie IF, Strain JJ (1996)The ferric reducing ability of plasma (FRAP) as a measure of "antioxidant power": the FRAP assay. Analytical Biochemistry 239: 70-76.

Bertram L, Tanzi RE (2008) Thirty years of Alzheimer's disease genetics: the implications of systematic meta-analyses. Nature Reviews Neuroscience 9: 768-778.

Borenstein AR, Mortimer JA, Ding D, Schellenberg GD, DeCarli C, Zhao Q, Copenhaver C, Guo Q, Chu S, Salmon DP, Galasko D (2010) Effects of apolipoprotein E- $\varepsilon 4$ and- $\varepsilon 2$ in amnestic mild cognitive impairment and dementia in Shanghai: SCOBHI-P. American Journal of Alzheimer's Disease \& Other Dementias 25: 233-238.

Bras J, Guerreiro R, Darwent L, Parkkinen L, Ansorge O, EscottPrice V, Hernandez DG, Nalls MA, Clark LN, Honig L S, Marder K (2014) Genetic analysis implicates APOE, SNCA and suggests lysosomal dysfunction in the etiology of dementia with Lewy bodies. Human molecular genetics 23: 6139-6146.

Bu G (2009) Apolipoprotein E and its receptors in Alzheimer's disease: pathways, pathogenesis and therapy. Nature Reviews Neuroscience 10: 333-344.

Cacabelos R (2008) Pharmacogenomics in Alzheimer's disease. Pharmacogenomics in Drug Discovery and Development: From Bench to Bedside 448: 213-357. 
Castro-Chavira S, Fernandez T, Nicolini H, Diaz-Cintra S, PradoAlcala R (2015). Genetic markers in biological fluids for agingrelated major neurocognitive disorder. Current Alzheimer Research 12: 200-209.

Cervellati C, Romani A, Seripa D, Cremonini E, Bosi C, Magon S, Passaro A, Bergamini CM, Pilotto A, Zuliani G (2014) Oxidative balance, homocysteine, and uric acid levels in older patients with Late Onset Alzheimer's Disease or Vascular Dementia. Journal of the neurological sciences 337 : 156-161.

Chang YT, Chang WN, Tsai NW, Huang CC, Kung CT, Su YJ, Lin WC, Cheng BC, Su CM, Chiang YF, Lu CH (2014) The roles of biomarkers of oxidative stress and antioxidant in Alzheimer's disease: a systematic review. BioMed research International, $10.1155 / 2014 / 182303$.

Chen KL, Sun YM, Zhou Y, Zhao QH, Ding D, Guo QH (2016) Associations between APOE polymorphisms and seven diseases with cognitive impairment including Alzheimer's disease, frontotemporal dementia, and dementia with Lewy bodies in southeast China. Psychiatric genetics 26: 124.

Chico L, Simoncini C, Lo Gerfo A, Rocchi A, Petrozzi L, Carlesi C, Volpi L, Tognoni G, Siciliano G, Bonuccelli U (2013) Oxidative stress and APO E polymorphisms in Alzheimer's disease and in mild cognitive impairment. Free radical research 47: 569-576.

Corder EH, Saunders AM, Strittmatter WJ, Schmechel DE, Gaskell PC, Small GA, Roses AD, Haines JL, Pericak-Vance MA (1993) Gene dose of apolipoprotein E type 4 allele and the risk of Alzheimer's disease in late onset families. Science 261: 921-923.

Cristalli DO, Arnal N, Marra FA, de Alaniz MJ, Marra CA (2012) Peripheral markers in neurodegenerative patients and their firstdegree relatives. Journal of the neurological sciences, 314: 48-56.

D’Onofrio G, Sancarlo D, Seripa D, Ricciardi F, Giuliani F, Panza F, Greco A (2016) Non-Pharmacological Approaches in the Treatment of Dementia. In Update on Dementia: InTech $10.5772 / 64232$

Dewji NN, Singer SJ (1996) Genetic clues to Alzheimer's disease. Science 271: 159.

Dose J, Huebbe P, Nebel A, Rimbach G (2016) APOE genotype and stress response-a mini review. Lipids in health and disease 15 : 121.

Emi M, Wu LL, Robertson MA, Myers RL, Hegele RA, Williams RR, White R, Lalouel JM (1988) Genotyping and sequence analysis of apolipoprotein $\mathrm{E}$ isoforms. Genomics 3: 373-379.
Farrer LA, Cupples LA, Haines JL, Hyman B, Kukull WA, Mayeux R, Myers RH, Pericak-Vance MA, Risch N, Van Duijn CM (1997) Effects of age, sex, and ethnicity on the association between apolipoprotein E genotype and Alzheimer disease: a meta-analysis. Jama 278: 1349-1356.

Ferencz B, Gerritsen L. Genetics and underlying pathology of dementia (2015) Genetics and underlying pathology of dementia. Neuropsychology review 25: 113-124.

Frieden C, Garai K (2012) Structural differences between apoE3 and apoE4 may be useful in developing therapeutic agents for Alzheimer's disease. Proceedings of the National Academy of Sciences 109: 8913-8918.

Friedman J (2011) Why is the nervous system vulnerable to oxidative stress? In Oxidative stress and free radical damage in neurology. Springer 10.1007/978-1-60327-514-9_2: 19-27.

Guidi I, Galimberti D, Lonati S, Novembrino C, Bamonti F, Tiriticco M, Fenoglio C, Venturelli E, Baron P, Bresolin N, Scarpini E (2006) Oxidative imbalance in patients with mild cognitive impairment and Alzheimer's disease. Neurobiology of aging 27: 262-269.

Halliwell B, Gutteridge JM (2015) Free radicals in biology and medicine. Oxford University Press, USA (Ed. 5).

Harold D, Abraham R, Hollingworth P, Sims R, Gerrish A, Hamshere ML, Pahwa JS, Moskvina V, Dowzell K, Williams A, Jones N (2009) Genome-wide association study identifies variants at CLU and PICALM associated with Alzheimer's disease. Nature genetics 41: 1088-1093.

Holtzman DM, Herz J, Bu G (2012) Apolipoprotein E and apolipoprotein E receptors: normal biology and roles in Alzheimer disease. Cold Spring Harbor perspectives in medicine 2 : a006312.

Huang Y (2010) A $\beta$-independent roles of apolipoprotein E4 in the pathogenesis of Alzheimer's disease. Trends in Molecular Medicine $16: 287-294$.

Huang Y, Mahley RW (2014) Apolipoprotein E: structure and function in lipid metabolism, neurobiology, and Alzheimer's diseases. Neurobiology of Disease 72: 3-12.

Ihara Y, Hayabara T, Sasaki K, Kawada R, Nakashima Y, Kuroda S (2000) Relationship between oxidative stress and apoE phenotype in Alzheimer's disease. Acta neurologica scandinavica $102: 346-349$. 
Iova A, Micle O, VICAȘ L, Micle L, Iova S, MUREȘAN M, IONIŢĂ CA (2014) Oxidative stress in Alzheimer's dementia. Age 50:58.

Jedenius E, Wimo A, Strömqvist J, Fastbom J, Winblad B, Winblad U, Andreasen N (2015) Comparing estimated cost per patient for dementia care: Two municipalities and Swedish national population data. Clinical Nursing Studies 3: 67.

Jellinger KA (2007) The enigma of mixed dementia. Alzheimer's \& Dementia 3: 40-53.

Kang R, Li P, Wang T, Li X, Wei Z, Zhang Z, Zhong L, Cao L, Heckman MG, Zhang YW, Xu H (2016) Apolipoprotein E epsilon 2 allele and low serum cholesterol as risk factors for gastric cancer in a Chinese Han population. Scientific Reports 6. doi: 10.1038/srep19930.

Leduc V, Domenger D, De Beaumont L, Lalonde D, BélangerJasmin S, Poirier J (2011) Function and comorbidities of apolipoprotein e in Alzheimer's disease. International Journal of Alzheimer's Disease 2011: 974361, DOI: http://dx.doi.org/10.4061/2011/974361.

Lee AY (2011) Vascular dementia. Chonnam Medical Journal 47: 66-71.

Liu CC, Kanekiyo T, Xu H, Bu G (2013) Apolipoprotein E and Alzheimer disease: risk, mechanisms and therapy. Nature Reviews Neurology 9: 106-118.

López-Riquelme N, Alom-Poveda J, Viciano-Morote N, LlinaresIbor I, Tormo-Díaz C (2016) Apolipoprotein E $\varepsilon 4$ allele and malondialdehyde level are independent risk factors for Alzheimer's disease. SAGE open medicine 4: 2050312115626731.

Luca M, Luca A, Calandra C (2015) The role of oxidative damage in the pathogenesis and progression of Alzheimer's disease and vascular dementia. Oxidative medicine and cellular longevity 2015: 504678. doi: 10.1155/2015/504678. .

Lundkvist J, Halldin MM, Sandin J, Nordvall G, Forsell P, Svensson S, Jansson L, Johansson G, Winblad B, Ekstrand J (2014) The battle of Alzheimer's Disease-the beginning of the future Unleashing the potential of academic discoveries. Frontiers in pharmacology 5: 102. doi: 10.3389/fphar.2014.00102..

Mahley RW, Huang Y (2012) Apolipoprotein e sets the stage: response to injury triggers neuropathology. Neuron 76: 871-885.

Mahley RW, Huang Y, Weisgraber KH (2006) Putting cholesterol in its place: apoE and reverse cholesterol transport. Journal of Clinical Investigation 116: 1226.
Moslemnezhad A, Mahjoub S, Moghadasi M (2016) Altered plasma marker of oxidative DNA damage and total antioxidant capacity in patients with Alzheimer's disease. Caspian Journal of Internal Medicine $7: 88$

Negahdar H, Hosseini SR, Parsian H, Kheirkhah F, Mosapour A, Khafri S, Haghighi AH (2015) Homocysteine, trace elements and oxidant/antioxidant status in mild cognitively impaired elderly persons: a cross-sectional study. Romanian Journal of Internal Medicine 53: 336-342.

Niedzielska E, Smaga I, Gawlik M, Moniczewski A, Stankowicz P, Pera J, Filip M (2016) Oxidative stress in neurodegenerative diseases. Molecular Neurobiology 53: 4094-4125.

Panza F, Frisardi V, Seripa D, D'Onofrio G, Santamato A, Masullo C, Logroscino G, Solfrizzi V, Pilotto A (2012) Apolipoprotein E genotypes and neuropsychiatric symptoms and syndromes in late-onset Alzheimer's disease. Ageing research reviews 11: 87-103.

Percy M, Somerville MJ, Hicks M, Colelli T, Wright E, Kitaygorodsky J, Jiang A, Ho V, Parpia A, Wong MK, Garcia A (2014) Risk factors for development of dementia in a unique sixyear cohort study. I. An exploratory, pilot study of involvement of the E4 allele of apolipoprotein E, mutations of the hemochromatosis-HFE gene, type 2 diabetes, and stroke. Journal of Alzheimer's Disease 38: 907-922.

Pham-Huy LA, He H, Pham-Huy C (2008) Free radicals, antioxidants in disease and health. International Journal of Biomedical Science 4: 89.

Popa-Wagner A, Mitran S, Sivanesan S, Chang E, Buga AM (2013) ROS and brain diseases: the good, the bad, and the ugly. Oxidative medicine and cellular longevity 2013: 963520, http://dx.doi.org/10.1155/2013/963520.

Prince M, Bryce R, Albanese E, Wimo A, Ribeiro W, Ferri CP (2013) The global prevalence of dementia: a systematic review and metaanalysis. Alzheimer's \& Dementia 9: 63-75. e62.

Pulido R, Jiménez-Escrig A, Orensanz L, Saura-Calixto F, Jiménez-Escrig A (2005) Study of plasma antioxidant status in Alzheimer's disease. European Journal of Neurology 12: 531-535.

Riddell DR, Zhou H, Atchison K, Warwick HK, Atkinson PJ, Jefferson J, Xu L, Aschmies S, Kirksey Y, Hu Y, Wagner E (2008) Impact of apolipoprotein $\mathrm{E}$ (ApoE) polymorphism on brain ApoE levels. Journal of Neuroscience 28: 11445-11453.

Ringman JM, Elashoff D, Geschwind DH, Welsh BT, Gylys KH, Lee C, Cummings JL, Cole GM (2012) Plasma signaling proteins 
in persons at genetic risk for Alzheimer disease: influence of APOE genotype. Archives of Neurology 69: 757-764.

Rohn TT (2014) Is apolipoprotein E4 an important risk factor for vascular dementia? International journal of clinical and experimental pathology 7: 3504 .

Rosini M, Simoni E, Minarini A, Melchiorre C (2014) Multitarget design strategies in the context of Alzheimer's disease: acetylcholinesterase inhibition and NMDA receptor antagonism as the driving forces. Neurochemical Research 39 : 1914-1923.

Rubino E, Vacca A, Govone F, De Martino P, Pinessi L, Rainero I (2013) Apolipoprotein E polymorphisms in frontotemporal lobar degeneration: a meta-analysis. Alzheimer's \& Dementia 9 : 706713.

Schrag M, Mueller C, Zabel M, Crofton A, Kirsch WM, Ghribi O, Squitti R, Perry G (2013) Oxidative stress in blood in Alzheimer's disease and mild cognitive impairment: a meta-analysis. Neurobiology of Disease 59: 100-110.

Sekler A, Jiménez JM, Rojo L, Pastene E, Fuentes P, Slachevsky A, Maccioni RB (2008) Cognitive impairment and Alzheimer's disease: Links with oxidative stress and cholesterol metabolism. Neuropsychiatric Disease and Treatment $4: 715$.

Thakur ME (2015) The American psychiatric publishing textbook of geriatric psychiatry: American Psychiatric Publishing. ISBN $1585624845,9781585624843$.

Verghese PB, Castellano JM, Holtzman DM (2011) Apolipoprotein E in Alzheimer's disease and other neurological disorders. The Lancet Neurology 10: 241-252.

Villeneuve S, Brisson D, Marchant NL, Gaudet D (2014) The potential applications of Apolipoprotein $\mathrm{E}$ in personalized medicine. Frontiers in Aging Neuroscience 6: 154. doi: 10.3389/fnagi.2014.00154.

Vos SJ, Van Rossum IA, Verhey F, Knol DL, Soininen H, Wahlund LO, Hampel H, Tsolaki M, Minthon L, Frisoni GB, Froelich L (2013). Prediction of Alzheimer disease in subjects with amnestic and nonamnestic MCI. Neurology 80: 1124-1132.
Walker Z, Possin KL, Boeve BF, Aarsland D (2015) Lewy body dementias. The Lancet 386 : 1683-1697.

Wang Z, Ma W, Rong Y, Liu L (2014) The association between apolipoprotein $\mathrm{E}$ gene polymorphism and mild cognitive impairment among different ethnic minority groups in China. International Journal of Alzheimer's Disease 2014: 150628. doi: $10.1155 / 2014 / 150628$.

Williams JW, Plassman BL, Burke J, Holsinger T, Benjamin S (2010) Preventing Alzheimer's disease and cognitive decline. Evidence report/technology assessment No. 193.(Prepared by the Duke Evidence-based Practice Center under Contract No. HHSA 290-2007-10066-I.) AHRQ Publication No. 10-E005. InAHRQ Publication No. 10-E005 2010. Agency for Healthcare Research and Quality Rockville, MD.

World Health Organization (2012) Dementia: Fact Sheet Number 362. Retreived from: http://www. who. int/mediacentre/factsheets/fs362/en.

Yan W, Wei P, Xuan Y, Guo Y, Li X, Song Y, Fang K (2016) Relationship between apolipoprotein $\mathrm{E}$ gene polymorphism and Parkinson's disease: a meta-analysis. International Journal of Clinical and Experimental Medicine 9: 5334-5346.

Zafrilla P, Mulero J, Xandri JM, Santo E, Caravaca G, Morillas JM (2006) Oxidative stress in Alzheimer patients in different stages of the disease. Current medicinal chemistry 13: 1075-1083.

Zhou Q, Peng D, Yuan X, Lv Z, Pang S, Jiang W, Yang C, Shi X, Pang G, Yang Y, Xie H (2014) APOE and APOC1 gene polymorphisms are associated with cognitive impairment progression in Chinese patients with late-onset Alzheimer's disease. Neural Regeneration Research 9: 653.

Zito G, Polimanti R, Panetta V, Ventriglia M, Salustri C, Siotto MC, Moffa F, Altamura C, Vernieri F, Lupoi D, Cassetta E (2013) Antioxidant status and APOE genotype as susceptibility factors for neurodegeneration in Alzheimer's disease and vascular dementia. Rejuvenation Research 16: 51-56.

Zlokovic BV (2011) Neurovascular pathways to neurodegeneration in Alzheimer's disease and other disorders. Nature Reviews Neuroscience 12: 723-738. 